\title{
Treatment of $Q$ fever in beef cattle in Queensland, Australia: historical context, present scenario and future perspectives
}

\begin{abstract}
The intracellular bacterium Coxiella burnetii is a dual pathogen of domestic ruminants and humans. Outbreaks of infection in cattle may have public health implications for the resident population of regional and rural Queensland, home to the Australian beef industry. The ensuing disease, so-called Q fever, causes abortion in livestock, and, if transmitted to humans by inhalation of aerosols, either a mild yet debilitating acute flu-like illness or, rarely, chronic life-threating respiratory complications. The recent recognition of high seroprevalence rates in putatively low-risk communities has compounded a growing concern over inadequate implementation of effective disease control measures. Concurrently, in order to meet increasing present and future consumer demands for high-quality beef, cattle farmers are seekingoptimized reproductive performance and rapid weight gain. In vitro fertilization of elite animals is considered to represent the best option to introduce such highly desirable genetic traits into commercial cattle herds. In so doing, resistance to $C$. Burnetii infection may similarly be engineered in cattle by the advancement of genome editing technology.
\end{abstract}

Volume 2 Issue 2 - 2015

\author{
Dhruba Acharya,' Andrew W Taylor- \\ Robinson ${ }^{2}$ \\ 'Department of Microbiology- Division of Immunology, \\ Kathmandu University School of Medical Sciences, Nepal \\ ${ }^{2}$ School of Medical \& Applied Sciences, Central Queensland \\ University, Australia
}

\begin{abstract}
Correspondence: Andrew Taylor-Robinson, Professor of Immunology \& Haematology, School of Medical \& Applied Sciences, Central Queensland University, Bruce Highway, Rockhampton, QLD 4702,Australia, Tel 6174923 2008, Email a.taylor-robinson@cqu.edu.au
\end{abstract}

Received: March 12, 2014 | Published: April 29, 2015

Keywords: q fever, cattle, coxiella burnetii, treatment, vaccine, in vitro fertilization, gene editing

\section{Introduction}

Q fever is a zoonotic disease caused by Coxiella Burnetii, an obligate, intracellular, Gram-negative coccobacillus bacterium which is responsible for both acute and chronic manifestations. ${ }^{1}$ This ubiquitous pathogen is typically present in the udder and milk of infected livestock and is passed on in their faeces. It may also be shed in the products of conception, and on the neonate of an infected animal. In cattle, Q fever is a well-recognized cause of abortion, stillbirth and weak calves. ${ }^{2}$ Infection is transmitted to humans by inhalation of infected airborne particles, dander or dust during the handling or processing of animal products or by close proximity to infected animals when giving birth. ${ }^{3}$ Hence, farm hands and abattoir workers are at particular risk. ${ }^{4,5}$

Q fever was first observed as a clinical entity in the 1930s in Queensland, Australia, during an outbreak of respiratory illness in abattoir workers, when it was described as 'Query Fever'. ${ }^{67}$ The name has caused confusion, Q being misinterpreted as standing for Queensland rather than Query. ${ }^{8}$ Within a decade of the identification of infection, the bacterium was described as the causative agent, the reservoirs were identified and the routes of infections were elucidated. In the intervening period the pathogenicity, laboratory diagnosis and treatment strategies have been studied to an extent. Nonetheless, outbreaks at regular intervals across the globe indicate that the biomedical research community still has much to learn about this disease 80 years after its discovery.

Queensland is the second largest state in Australia, situated to the north east of the country, and contains human and beef cattle populations of more than 4.6 million and 13.4 million, respectively. ${ }^{9}$ The cattle industry continues to be a major contributor to the economy of Queensland, which has the most beef cattle in Australia and is also the greatest producer and exporter of both cattle and red meat. ${ }^{10}$ This article focuses on the current situation in Queensland in regard to Q fever and its association with cattle and humans, and considers strategies for future research that could be of benefit to prevent or control future outbreaks in this cattle-rich state.

\section{Clinical manifestations}

The incubation period for acute infection of humans is usually $2-3$ weeks. The most common manifestation is mild flu-like symptoms with abrupt onset of fever, malaise, profuse perspiration, severe headache, muscle pain, joint pain, loss of appetite, upper respiratory problems, dry cough, pleuritic pain, chills, confusion and gastrointestinal symptoms, such as nausea, vomiting and diarrhoea. ${ }^{1,6,11}$ The disease can progress to an atypical pneumonia, which can result in a life-threatening acute respiratory distress syndrome (ARDS). ${ }^{12}$ Despite this, around half of infected individuals exhibit no symptoms. As $\mathrm{Q}$ fever is often misdiagnosed due to its non-specific nature, many abattoir workers develop immunity to Q fever without an obvious illness. ${ }^{11}$ The chronic form of $\mathrm{Q}$ fever is virtually identical to inflammation of the inner lining of the heart (endocarditis), which can occur months or decades following the infection. It is usually fatal if untreated. However, with appropriate treatment, the mortality falls to around $10 \%{ }^{1}$

\section{Epizootiology and epidemiology}

C. Burnetii has a strong association with domestic ruminants, and contact with these animal and animal products is the primary route of human exposure to this pathogen. However, the range of natural reservoirs is extensive and includes both wild and domestic mammals, birds and arthropods. ${ }^{1}$ Nearly one hundred species of mammal, including marsupials native to Queensland, have been recorded as 
a reservoir of C. burnetii. Among breeding, domestic and laboratory animals, these are mainly horned cattle, sheep, goats, cats, dogs, guinea pigs and gerbils. Infection has also been detected in annelids, fish and reptiles. ${ }^{11-13}$

The initial transmission of $C$. Burnetii to livestock is thought to have been via ticks, which form part of the natural transmission cycle of the organism in wildlife. ${ }^{8}$ Kangaroos and bandicoots have been identified as potential reservoirs of Q fever in Australia. ${ }^{14,15}$ Cooper et al., ${ }^{16}$ have reported $22 \%$ seropositivity in dogs attending veterinary clinics in the Townsville region, Northern Queensland, and $17 \%$ seropositivity in beef cattle in the same location, from which they inferred canines and bovines may serve as potential reservoirs of Q fever infection in humans. ${ }^{16}$ Further, macropods - kangaroos and wallabies - are considered as atypical reservoirs. Seropositivity also occurs to a significant extent among dingo, brushtail possum, feral pig, feral cat and fox..$^{15}$ Tozer et al., ${ }^{17}$ investigated the possibility of the presence of $C$. Burnetii in a number of animal and environmental samples collected throughout Queensland in order to identify potential source(s) of human infection; of 1318 animal samples, 85 (15.5\%) tested positive. The profound population increase in Queensland over recent years has led to urban development of bush land. In turn, this has provided a potential passage for the transmission of $\mathrm{Q}$ fever from wild and feral animals to domestic animals and ultimately to humans. Although it is described elsewhere that wild animals and domestic cattle might be possible sources of human infection, as shown by raised seroprevalence rates observed in putatively high risk communities, this remains to be substantiated. Taken together, the identification of the causative agent in various environmental sources, $Q$ fever patients lacking direct animal contact and cases detected in low-risk urban environments has led researchers to aim to identify unequivocally the source and mode of transmission of Q fever in Queensland. ${ }^{17}$

\section{Clinical reports from Queensland: an amelio- rated or exacerbated situation?}

Gale et al. ${ }^{18}$ identified 27 cases of Q fever from Townsville Hospital during 1994-2006, where 18 patients were infected acutely and nine chronically. ${ }^{18}$ Also, Palmer et al. ${ }^{19}$ reported 191 notifications of this infection from Brisbane Southside Population Health Unit between January 2001 and September $2006 .{ }^{19}$ For the year 2006, Gidding et al. ${ }^{20}$ detected 107 Q fever infections per 100,000 residents in Queensland, for which the majority of cases located to the rural south west region. ${ }^{20}$ Tozer et al ${ }^{21}$ reported a very similar rate of seropositivity among the urban metropolitan Brisbane population. ${ }^{21}$ According to data from the Australian National Notifiable Diseases Surveillance System, Queensland has the highest rate of Q fever notification in Australia with 3.5 cases per 100,000 persons compared to the national average of 1.4 cases per 100,000 populations. ${ }^{9}$ Paradoxically, Tozer et al. ${ }^{21}$ reported a lower incidence rate in Queensland than for other states of Australia. ${ }^{21}$ The $5 \%$ seropositivity rate in Brisbane is lower than the $16 \%$ seropositivity reported some 30 years previously in the Queensland state capital, ${ }^{22} 7 \%$ in Southwest Queensland, ${ }^{23} 19 \%$ in Central Queensland, ${ }^{24} 11 \%$ and $27 \%$ in New South Wales, ${ }^{25,26} 45 \%$ seropositivity in Adelaide, ${ }^{27}$ and $66 \%$ in Western Australia. ${ }^{28}$

Q fever is a vaccine-preventable disease but despite the availability of an efficacious vaccine for administration to the general population of Queensland since 2001, high notification numbers are still recorded annually. ${ }^{20}$ The introduction of The National Q fever Management Program in Queensland from November 2001 increased the participation of high risk populations in the vaccination program where previously less than $65 \%$ inclusion was noted..$^{19,29}$ Unfortunately, principally due to economic considerations this program ceased nationally in July 2005 and in Queensland in December 2006. ${ }^{19}$ Since 1934 , when Q fever first became apparent to medical practitioners in Brisbane, outbreaks of this disease in Australia have been associated predominantly with abattoirs. ${ }^{30}$ Not only does Queensland have the largest head of cattle of any territory in Australia, beef production also represents the principal agricultural industry in the state. ${ }^{10}$ Therefore, it is of the utmost importance to determine the risk of microbial infection to this industry as well as to identify the potential sources of infection and routes of transmission. Such information will valuably inform public health policy to improve preparation against future outbreaks. The ongoing deficit in knowledge regarding the epidemiology of infection, notably identification of reservoirs and modes of transmission, was highlighted by an outbreak of Q fever at an Australian abattoir slaughtering feral goats, which resulted in a failure to follow procedures to reduce the production of bacteriacontaining aerosols. ${ }^{31}$

\section{Major recent outbrealks: surprise packages and lessons to learn}

Most of the Q fever outbreaks that have been reported are from rural settings which are associated directly or indirectly with farms or farm animals. However, urban outbreaks have been described following confirmed exposure to animal products. ${ }^{32-34}$ In some of these, the source of infection remains a mystery. ${ }^{35}$ Several recent incidences of $\mathrm{Q}$ fever have exemplified the gravity of the epidemiology of this infection. A major outbreak of $Q$ fever in an urban school in Israel was possibly transmitted through an air-conditioning system. ${ }^{36}$ This case is unique in its magnitude and setting since there was no proximity to livestock or their products. The largest $\mathrm{Q}$ fever outbreak occurred in an area of the southern Netherlands where initial disease notification was not recorded. Over a span of three years, more than 3,000 cases were detected. ${ }^{37}$ However, these were clearly associated with highdensity dairy goat farming.

The continual notifications of $\mathrm{Q}$ fever among so-called lowrisk populations in Queensland, ${ }^{21}$ together with the occurrence of noteworthy outbreaks among urban populations globally, ${ }^{36}$ have challenged the relevant government agencies and public health authorities to focus resources to identify the possibility of future outbreaks.

\section{Treatment and prophylaxis: is it enough?}

For treatment of acute $\mathrm{Q}$ fever cases, a standard course of antibiotics belonging to the drug groups tetracyclines (doxycycline, glycylcycline), macrolides (erythromycin, clarithromycin, roxithromycin) and quinolones (ciprofloxacin, ofloxacin, trovafloxacin) is recommended. ${ }^{38}$ Long-term antibiotic therapy and cardiac surgery are recommended in order to treat chronic Q fever infection depending on the particular condition of each patient. ${ }^{39} \mathrm{New}$ generation antibiotics are being applied in clinical trials. ${ }^{40,41}$ In some paediatric cases, gamma-interferon is the treatment of choice. ${ }^{42}$

The Australian National Vaccination Program was launched in 2001. Q-VAX is the only commercially available human Q fever vaccine, composed of formalin-inactivated C. Burnetii (CSL, Parkville, Vic, Australia).$^{20}$ Although the seroconversion rate is low (50-80\%) and antibody levels are transient, cell-mediated immunity 
develops. Clinical trials have demonstrated a high degree of efficacy. IND 610 is another vaccine based on formalin inactivation of whole bacterial cells, prepared in USA, but now no longer licensed in most countries for which $\mathrm{Q}$ fever is endemic. ${ }^{43}$ Coxevac is a vaccine trialed in the Netherlands in sheep and dairy goats. It aims to reduce shedding of new bacteria and has shown promise in the reduction of new cases. ${ }^{44}$ Chlamyvax FQ, a killed C. Burnetii vaccine combined with a killed vaccine against Chlamydophila abortus, is commercially available in France for animal administration. ${ }^{33}$ Experimental inoculation of $C$. Burnetii in cattle induces not only respiratory disorders and cardiac failures but also frequent abortions.

Despite the availability of vaccination, the prevention of Q fever infection may be best achieved by animal quarantine, culling of sick animals and isolation of microbes in the case of disease occurrence. ${ }^{45}$ Antibiotic therapy can be administered to individuals who are already infected and vaccination can be applied - to humans or animals-in order to reduce the transmission of infection. Nevertheless, the question remains as to whether sufficient is being done to combat $\mathrm{Q}$ fever and if we doing enough to manage the possible outbreak of infection? This issue is of particular relevance to Central Queensland, with its capital city, Rockhampton, recognized as the "beef capital of Australia". ${ }^{6}$

\section{Future perspectives: IVF of cattle and gene engineering techniques}

Q fever remains "a tough nut to crack" ${ }^{47}$ C. Burnetii resides and reproduces within the acidified environment of a lysosomal parasitophorous vacuole of a macrophage. ${ }^{48}$ Genes critical to survival in this hostile niche are involved in invasion and modulation of the host cell via mechanisms of DNA repair and homologous recombination. ${ }^{48,49}$ The availability of genetic information forisolates of $C$. Burnetii at circulate in Queensland is very limited. Genetic characterization of DNA samples originating from the state and comparative analysis of their sequences with those of previously identified genotypes will enable the identification of novel marker(s) of virulence. In addition to its direct value to genome editing, genotyping of bacteria is critical for diagnosis, treatment and epidemiological surveillance. It is acknowledged that if the beef cattle industry in Australia were to experience a significant outbreak of $\mathrm{Q}$ fever the potential impact on the economy would be profound. ${ }^{10}$ Therefore, resources should be focused to avoid such a scenario. One possible strategy, yet to be considered, is the development of genome engineering and its application through in vitro fertilization (IVF). An enhanced ability to modify the genomes of livestock species could be utilized as a means to improve resistance to a variety of infectious diseases, including Q fever. There are several methods of genome alteration that have been devised in recent years for use in mammals. The generation of a knockout cell line followed by somatic cell nuclear transfer is the protocol of choice for many applications despite its requirement for technical expertise. ${ }^{50}$ Embryo microinjection, ${ }^{51}$ cloning strategy in combination with zinc finger nucleases, ${ }^{52-54}$ cytoplasmic injection of zygotes with editor Mrna,${ }^{55}$ and injection of TALEN mRNA into zygotes followed by transfer into synchronized recipients ${ }^{56}$ are a few of the techniques that have been implemented by the IVF research community.

\section{Conclusion}

In relation to beef cattle realistically attainable goals in rapid growth, high quality beef production and optimized reproductive performances may be achieved by developing new technologies in the field of IVF. ${ }^{57}$ In 2013, the first cloned calf with enhanced genetics was bred in Queensland. ${ }^{58}$ In future, IVF will be applied more widely to the breeding of beef cattle in order to address the increasing demand from domestic and international consumers for high quality beef. While lean meat is the primary objective, ${ }^{59}$ it is feasible that the same geneediting strategy may be used in tandem in order to introduce genetic resistance to $\mathrm{Q}$ fever infection. In this context, an important recent milestone is the full genome sequencing of C. Burnetii isolated from an Australian acute Q fever patient. ${ }^{60}$ This represents the first whole genome from this historical Q fever country and should enhance the molecular characterization of this intriguing and important query pathogen.

\section{Acknowledgements}

None.

\section{Conflict of interest}

Author declares that there is no conflict of interest.

\section{References}

1. Maurin M, Raoult D. Q fever. Clin Microbiol Rev. 1999;12(4):518-553.

2. Agerholm JS. Coxiella burnetii associated reproductive disorders in domestic animals-a critical review. Acta Vet Scand. 2011;55:13.

3. Georgiev M, Afonso A, Neubauer H, et al. Q fever in humans and farm animals in four European countries, 1982 to 2010. Euro Surveill. 2013;18(8):20407

4. Carrieri MP, Tissot-Dupont H, Rey D, et al. Investigation of a slaughter house-related outbreak of Q fever in the French Alps. Eur J Clin Microbiol Infect Dis. 2002;21(1):17-21.

5. Wilson LE, Couper S, Prempeh H, et al. Investigation of a Q fever outbreak in a Scottish co-located slaughterhouse and cutting plant. Zoonoses Public Health. 2010;57(7-8): 493-498.

6. Derrick EH. Q fever, a new fever entity: clinical features, diagnosis and laboratory investigation. Rev Infect Dis. 1937;5(4):790-800.

7. Derrick EH. The epidemiology of Q fever. J Hyg. 1944;43(5):357-361.

8. McDade JE. Evidence supporting the hypothesis that rickettsial virulence factors determine the severity of spotted fever and typhus group infections. Ann NY Acad Sci. 1990;590:20-26.

9. Australian Bureau of Statistics. Annual report 2012-2013. 2014.

10. State of Queensland, Department of Employment, Economic Development and Innovation. The Queensland beef industry: current trends and future projections. Updated August 2010. Brisbane, Australia: Queensland Government. 2010. p. 1-47.

11. Marrie TJ. Q fever - a review. Can Vet J. 1990;31(8):555-563.

12. Marrie TJ. Coxiella burnetii pneumonia. Eur Respir J. 2003;21(4):713-719.

13. Platt-Samoraj A, Ciecierski H, Michalski M. Role of goats in epizootiology and epidemiology of Q fever. Pol J Vet Sci. 2005;8(1):79-83.

14. Banazis MJ, Bestall AS, Reid SA, et al. A survey of western Australian sheep, cattle and Kangaroos to determine the seroprevalence of Coxiella burnetii. Vet Microbiol. 2010;143(2-4):337-345.

15. Cooper A, Goullet M, Mitchell J, et al. Serological evidence of Coxiella burnetii exposure in native marsupials and introduced animals in Queensland, Australia. Epidemiol Infect. 2012;140(7):1304-1308. 
16. Cooper A, Hedlefs R, McGowan M, et al. Serological evidence of Coxiella burnetii infection in beef cattle in Queensland. Aust Vet J. 2011;89(7):260-264.

17. Tozer SJ, Lambert SB, Strong CL, et al. Potential animal and environmental sources of Q fever infection for humans in Queensland. Zoonoses Public Health. 2014;61(2):105-112.

18. Gale M, Ketheesan N, Govan B, et al. Q fever cases at a North Queensland center during 1994-2006. Intern Med J. 2007;37(9):644-646.

19. Palmer C, McCall B, Jarvinen K, et al. "The dust hasn't settled yet": the National Q Fever Management Program, missed opportunities for vaccination and community exposures. Aust $N$ Z J Public Health. 2007;31(4):330-332.

20. Gidding HF, Wallace C, Lawrence GL, et al. Australia's national Q fever vaccination program. Vaccine. 2009;27(14):2037-2041.

21. Tozer SJ, Lambert SB, Sloots TP, et al. Q fever seroprevalence in metropolitan samples is similar to rural/remote samples in Queensland, Australia. Eur J Clin Microbiol Infect Dis. 2011;30(10):1287-1293.

22. McKelvie P. Q fever in a Queensland meatworks. Med J Aust. 1980;1(12):590-593.

23. Parker N, Robson J, Bell M. A serosurvey of Coxiella burnetii infection in children and young adults in South West Queensland. Aust N Z J Public Health. 2010;34(1):79-82.

24. Taylor R, Hunter I, Tan R. Short report: prevalence of markers of exposure to Q fever in rural central Queensland. Commun Dis Intell. 2001;25(4):285-287.

25. Casolin A. Q fever in New South Wales Department of Agriculture workers. J Occup Environ Med. 1999;41(4):273-278.

26. Hutson B, Deaker RA, Newland J. Vaccination of cattle workers at risk of Q fever on the north coast of New South Wales. Aust Fam Physician. 2000;29(7):708-709.

27. Marmion BP, Ormsbee RA, Kyrkou M, et al. Vaccine prophylaxis of abattoir-associated Q fever. Lancet. 1984;2(8417-8418):1411-1414.

28. Mak DB, Fry DF, Bulsara MK. Prevalence of markers of Q fever exposure in the Kimberley, Western Australia. Commun Dis Intell. 2003;27(2):267-271.

29. Kermode K, Yong K, Hurley S, et al. An economic evaluation of increased uptake in $\mathrm{Q}$ fever vaccination among meat and agricultural workers following implementation of the National Q Fever Management Program. Aust NZ J Public Health. 2003;27(4):390-398.

30. Derrick EH. The course of infection with Coxiella burnetii. Med J Aust. 1973;1(21):1051-1057.

31. Buckley B. Q fever epidemic in Victorian general practice. Med J Aust. 1980;1(12):593-595.

32. Brouqui P, Badiaga S, Raoult D. Q fever outbreak in homeless shelter. Emerg Infect Dis. 2004;10(7):1297-1299.

33. Arricau-Bouvery N, Rodolakis A. Is Q fever an emerging or re-emerging zoonosis? Vet Res. 2005;36(3):327-349.

34. Parker NR, Barralet JH, Bell AM. Q fever. Lancet. 2006;367(9511):679-688.

35. Steiner HA, Raveh D, Rudensky B, et al. Outbreak of Q fever among kitchen employees in an urban hospital. Eur J Clin Microbiol Infect Dis. 2001;20(12):898-900.

36. Amitai Z, Bromberg M, Bernstein M, et al. A large $Q$ fever outbreak in an urban school in central Israel. Clin Infect Dis. 2010;50(11):1433-1438.
37. Schneeberger PM, Hermans MH, van Hannen EJ, et al. Real-time PCR with serum samples is indispensable for early diagnosis of acute Q fever. Clin Vaccine Immunol. 2010;17(2):286-290.

38. Hartzell JD, Wood-Morris RN, Martinez LJ, et al. Q fever: epidemiology, diagnosis, and treatment. Mayo Clin Proc. 2008;83(5):574-579.

39. Niemczuk K, Szymańska-Czerwińska M. Epidemiology, zoonotic aspect and current epidemiological situation of Q fever in Poland. In: Perez-Marin CC, editor. A Bird's Eye View of Veterinary Medicine. Intech: Rijeka, Croatia; 2012. p. 380-392.

40. Rolain JM, Lambert F, Raoult D. Activity of telithromycin against thirteen new isolates of $\mathrm{C}$. burnetii including three resistant to doxycycline. Ann N Y Acad Sci. 2005;1063:252-256.

41. Spyridaki I, Psaroulaki A, Vranakis I, et al. Bacteriostatic and bactericidal activities of tigecycline against Coxiella burnetii and comparison with those of six other antibiotics. Antimicrob Agents Chemother. 2009;53(6):2690-2692.

42. Maltezou HC, Raoult D. Q fever in children. Lancet Infect Dis. 2002;2(11):686-691.

43. Madariaga MG, Rezai K, Trenholme GM, et al. Q fever: a biological weapon in your backyard. Lancet Infect Dis. 2003;3(11):709-721.

44. Hogerwerf L, van den Brom R, Roest HI, et al. Reduction of Coxiella burnetiiprevalence by vaccination of goats and sheep, The Netherlands. Emerg Infect Dis. 2011;17(3):379-386.

45. Bielawska-Drózd A, Cieślik P, Mirski T, et al. Q fever-selected issues. Ann Agric Environ Med. 2013;20(2):222-232.

46. McDonald L. Beef Capital. In: An Overview of Rockhampton's History. 2003. p. 3-4.

47. McCaughey C. Q fever: a tough zoonosis. Vet Rec. 2014;175(1):15-16.

48. van Schaik EJ, Chen C, Mertens K, et al. Molecular pathogenesis of the obligate intracellular bacterium Coxiella burnetii. Nat Rev Microbiol. 2013;11(8):561-573.

49. Mertens K, Lantsheer L, Ennis DG, et al. Constitutive SOS expression and damage-inducible AddAB-mediated recombinational repair systems for Coxiella burnetii as potential adaptations for survival within macrophages. Mol Microbiol. 2008;69(6):1411-1426.

50. Kurome M, Geistlinger L, Kessler B, et al. Factors influencing the efficiency of generating genetically engineered pigs by nuclear transfer: multi-factorial analysis of a large data set. BMC Biotechnol. 2013;13:43.

51. Tan WS, Carlson DF, Walton MW, et al. Precision editing of large animal genomes. Adv Genet. 2012;80:37-97.

52. Hauschild J, Petersen B, Santiago Y, et al. Efficient generation of a biallelic knockout in pigs using zinc-finger nucleases. Proc Natl Acad Sci USA. 2011;108(29):12013-12017.

53. Liu X, Wang Y, Tian Y, et al. Generation of mastitis resistance in cows by targeting human lysozyme gene to $\beta$-casein locus using zinc-finger nucleases. Proc Biol Sci. 2014;281(1780):20133368.

54. Zhang C, Wang L, Ren G, et al. Targeted disruption of the sheep MSTN gene by engineered zinc-finger nucleases. Mol Biol Rep. 2014;41(1):209-215.

55. Geurts AM, Cost GJ, Freyvert Y, et al. Knockout rats via embryo microinjection of zinc-finger nucleases. Science. 2009;325(5939):433.

56. Proudfoot C, Carlson DF, Huddart R, et al. Genome edited sheep and cattle. Transgenic Res. 2015;24(1):147-153. 
57. Taylor-Robinson AW, Walton S, Swain DL, et al. The potential for modification in cloning and vitrification technology to enhance genetic progress in beef cattle in Northern Australia. Anim Reprod Sci. 2014;148(3-4):91-96.

58. Taylor-Robinson AW, Walton S, Vajta G. Production of a healthy far$\mathrm{m}$-born calf by modified somatic cell nuclear transfer. Int J Livest Res. 2014;4(2):99-104.
59. Kelly MJ, Tume RK, Fortes M, et al. Whole-genome association study of fatty acid composition in a diverse range of beef cattle breeds. J Anim Sci. 2014;92(5):1895-1901.

60. Walter MC, Vincent GA, Stenos J, et al. Genome sequence of Coxiella burnetii strain AuQ01 (Arandale) from an Australian patient with acute Q fever. Genome Announc. 2014;2(5):e00964-e001014. 